\title{
Addressing Uncertainty in Temporal and Spatial Scheduling for Farm Machinery Operation
}

\author{
Caicong Wu', ${ }^{1,2}$, in Zhou', Peng Qiao1, Jie Wang1 \\ ${ }^{1}$ College of Information and Electrical Engineering, China Agricultural University, Beijing, China \\ ${ }^{2}$ Department of Soil \& Crop Sciences, Texas A\&M University, College Station, USA \\ Email:wucc@cau.edu.cn
}

Received 21 December 2015; accepted 21 February 2016; published 24 February 2016

Copyright (C) 2016 by authors and Scientific Research Publishing Inc.

This work is licensed under the Creative Commons Attribution International License (CC BY).

http://creativecommons.org/licenses/by/4.0/

(c) (;) Open Access

\begin{abstract}
Uncertainty is an important characteristic of scheduling model for scale farm machinery operation organizing. Practice shows that scheduling model without considering uncertainties is nearly useless. Uncertain influence factors arisen from natural environment, society and economy, market and supply, and customer and behavior, exist widely, emerge frequently, and affect production deeply. Uncertainties interfere with the allocation of productive factors on temporal and spatial dimensions for farm machinery operation scheduling and management. Questionnaire for farm machinery organizations was designed and finished in 2014. Both occurrence frequency and influence degree for each factor were quantified. Four influence factors including operation location change, weather mutation, parts supply delay, and operation skill defects appear in both list of high occurrence and deep influence. Then results of questionnaire and results of specific investigation were used to study temporal and spatial scheduling model and system for farm machinery management. Three case studies are introduced. The first case is about the uncertainty and countermeasure of forage harvesters scheduling and monitoring for a professional forage plantation company. The second case is about the uncertainty and counter measure of cotton-picker scheduling and monitoring for a professional cotton picking company. And the third case is about the uncertainty and countermeasure of social service management for a professional cooperative. The cases show that the research has strong pertinence to deal with uncertainties and can improve management efficiency of farm machinery operation.
\end{abstract}

\section{Keywords}

Uncertainty, Influence Factor, Farm Machinery, Schedule, Model, GNSS 


\section{Introduction}

Computer based scheduling model and system are necessary for farm machinery organizations nowadays, since operation area is becoming larger and farm machinery scale is becoming bigger in China. Quick development of farm machinery social service improves the above changes [1] [2]. Researches on farm machinery operation scheduling mainly concentrate on operation scheduling under certainty circumstance by using the methods of operational research and spatial analyst [3]-[7]. One research [8] shows that the execution of an optimal schedule was found to give a reduction of $9.8 \%$ in the total time as compared to a schedule based on the tacit knowledge of the operations manager. However, in farm practice, farm machinery operation is easily and always affected by the uncertainty influence factors, such as weather mutation, mechanical failure, order cancellation, and unprofessional operation. And small disturbance from uncertainty factors may cause overall operation instability, and seriously disturb the whole operation plan. Practices show that scheduling model without considering uncertainties is nearly useless. David [9] proposed that the influence of uncertainty factors should be considered during farm machinery allocating and scheduling. Bochtis et al. [10] suggested that the uncertainty factors should be analyzed in advance to deal with their influences, in order to improve efficiency of scheduling model. The model was tested for a harvesting period of two years, and based on the analysis results, the percentage of successful suggestions ranged from $83.33 \%$ to $94.61 \%$. The strategy of Bochtis is the active strategy and has good reference value. In further, an uncertainty above $6 \%$ will imply unstable solutions, where for example in the case of $20 \%$ uncertainty, only $75 \%$ of the derived solutions will coincide with the baseline solution [8].

People pay more and more attention to uncertainty problems gradually since they need practical model of farm machinery scheduling [11]-[13]. Therefore the uncertainty problem must be solved scientifically and comprehensively in time. We designed questionnaire and got response of occurrence frequency and influence degree of each influence factor. In this paper, we use the data of top 5 influence factors as guidance to study and develop dispatching, scheduling, and monitoring model and system for large scale farm machinery companies.

\section{Materials and Methods}

We defined sources of uncertainty influence factors as five types: nature and environment, market and supply, customer and behavior, society and economy, and others. In further, we defined influence factors of each source as Table 1, according to the theoretical research and practice of farm machinery operations.

For each influence factor, we wanted to statistic its occurrence frequency (probability of occurrence) and influence degree (severity of influence). Answers for occurrence frequency question are defined as five levels including always, often, usually, occasionally, and never, and answers for influence degree question are also defined as five levels including deadly, seriously, ordinarily, slightly, and none.

We put the questionnaires on the Internet and invited respondents to finish it in 2014.The website of the questionnaire is http://www.sojump.com/jq/3307013.aspx, also our respondents are Chinese, the questionnaire was designed into Chinese version. Fifty valid cooperative questionnaires were returned, which came from seven provinces including Beijing, Tianjin, Heilongjiang, Xinjiang, Hebei, Shanxi, and Anhui.

\section{Results}

\subsection{Uncertainty Influence Analysis of Influence Factors Investigation}

We defined value of high occurrence $\left(V_{o}\right)$ as sum of proportions of the first three answers, i.e., always, often, and usually, and defined value of deep influence $\left(V_{i}\right)$ as sum of proportions of the first three answers, i.e., deadly, seriously, ordinarily.

As Table 2 and Table 3 show, four influence factors including operation location change, weather mutation, parts supply delay, and operation skill defects appear in both list of high occurrence and deep influence. The appearance means these influence factors often happen and affect farm machinery operation seriously, which should be paid more attention to during the production planning. Except for the above four influence factors, other influence factors listed in Table 2 and Table 3 also should be well dealt with, such as mechanical failure, operation area change, pests $\&$ diseases, operation duration change, etc. As a result, influence factors of market and supply occupy the largest proportion. 
Table 1. Uncertainty influence factors of farm machinery operation.

\begin{tabular}{|c|c|c|}
\hline No. & Source & Influence factors \\
\hline (1) & Nature and environment & $\begin{array}{c}\text { Weather mutation } \\
\text { Pests \& diseases } \\
\text { Soil environment incompatibility }\end{array}$ \\
\hline (2) & Market and supply & $\begin{array}{c}\text { Mechanical failure } \\
\text { Machine aging } \\
\text { Incompatibility between agronomy and machine } \\
\text { Operation order increasing } \\
\text { Operation order cancelation } \\
\text { Operation area change } \\
\text { Operation location change } \\
\text { Operation sequence change } \\
\text { Operation time change } \\
\text { Operation quality change } \\
\text { Operation price change } \\
\text { Operation duration change } \\
\text { Driver illness } \\
\text { Operation skill defects } \\
\text { Material supply }\end{array}$ \\
\hline (3) & Customer and behavior & $\begin{array}{c}\text { Miscommunication } \\
\text { Customer barrier } \\
\text { Unprofessional operation } \\
\text { Mechanical maintenance delay }\end{array}$ \\
\hline (4) & Society and economy & $\begin{array}{l}\text { Government compulsory policy } \\
\text { Government fine } \\
\text { Farm machinery subsidies change } \\
\text { Unfair competition }\end{array}$ \\
\hline (5) & Others & $\begin{array}{l}\text { Accident of road transportation } \\
\text { Lost on the road } \\
\text { Field location inaccurate }\end{array}$ \\
\hline
\end{tabular}

Table 2. Top 10 influence factors with high value of occurrence $\left(V_{o}\right)$.

\begin{tabular}{ccc}
\hline Rank & Influence factor & Value of high occurrence/\% \\
\hline 1 & Operation location change & 41.8 \\
2 & Machine aging & 41.8 \\
3 & Operation order change & 40.0 \\
4 & Weather mutation & 38.2 \\
5 & Operation area change & 38.2 \\
6 & Operating time change & 32.7 \\
7 & Parts supply delay & 30.9 \\
8 & Malignant competition & 29.1 \\
9 & Incompatibility between agronomy and machine & 29.1 \\
10 & Operation skill defects & 27.3 \\
\hline
\end{tabular}

Table 3. Top 10 influence factors with high value of influence $\left(V_{i}\right)$.

\begin{tabular}{ccc}
\hline Rank & Influence factor & Value of deep influence/\% \\
\hline 1 & Mechanical failure & 69.1 \\
2 & Weather mutation & 69.1 \\
3 & Parts supply delay & 54.5 \\
4 & Pests \& diseases & 52.7 \\
5 & Operation duration change & 49.1 \\
6 & Operation skill defects & 49.1 \\
7 & Soil environment incompatibility & 49.1 \\
9 & Operation location change & 45.5 \\
\hline
\end{tabular}




\subsection{Case 1: Uncertainty and Counter Measure for Forage Harvesting Company}

China Huishan Dairy Holdings Company Ltd. (Huishan) owns about 40,000 ha fields to produce forage and more than 600 farm machinery to work for itself. Fields are divided into ten operation areas. They bought all farm machinery, and hire temporary workers. As Figure 1, Huishan has more than 70 forage harvesters of CLAAS, a well-known company from Germany. For each harvester, more than ten or twenty trucks would work with it.

As a self-sufficiency company, Huishan do not need to coordinate with the customers during farm operation. And it is also not afraid of harvesting order change. The top 5 uncertainties of Huishan as following: 1) weather mutation, 2) assets and material loss, 3) mechanical failure, 4) operation skill defects, and 5) machine aging.

The first influence factor, weather mutation, is out of control to the company. What the company can do is to get the weather information as early as possible and adjust its plantation plan in time.

The second influence factor, assets and material loss, caused by employers, arises from specific employment relationship. "Inside job” causes heavy losses, such as seed and fertilizer, to the company every year. In Huishan, fields, crop, tractors, and implements do not belong to drivers, which is different from classical family farms owning everything. Therefore, the company and the employer should be responsible for operation progress and operation quality [2], and need to monitor the whole operation progress of farm machinery to collect information like tractor, implement, and labor. Strategy to deal with the uncertainty influence is to establish a GNSS and camera based system to monitor the whole production process (as Figure 2).

As Figure 2 and Figure 3, both real-time position and videos would be recorded during farm operation. To save cost of data transferring, video will only be copied and replayed if something happened or its historic tracks outside the fields and normal roads. With the positions and videos, the employer and manager can well monitor whole farm production to avoid assets and material loss.

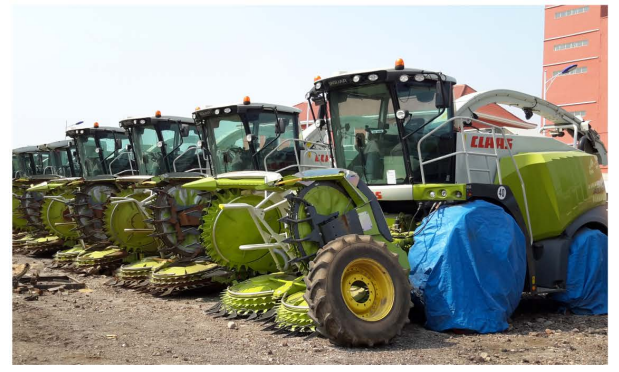

(a)

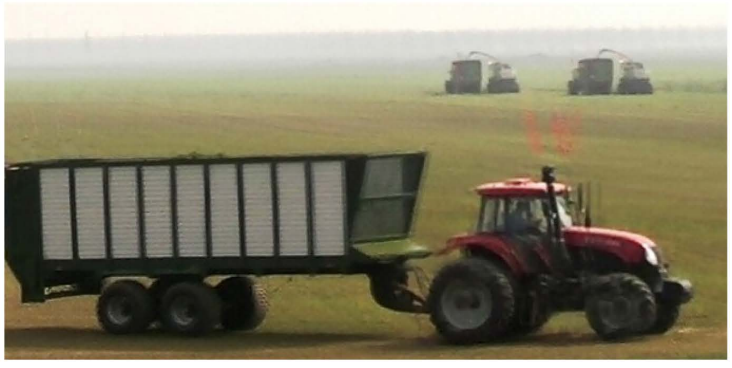

(b)

Figure 1. Farm machinery for forage harvesting of Huishan. (a) shows forage harvester; (b) shows forage transportation truck. Forage transportation truck which moves forages from field to dairy farm.

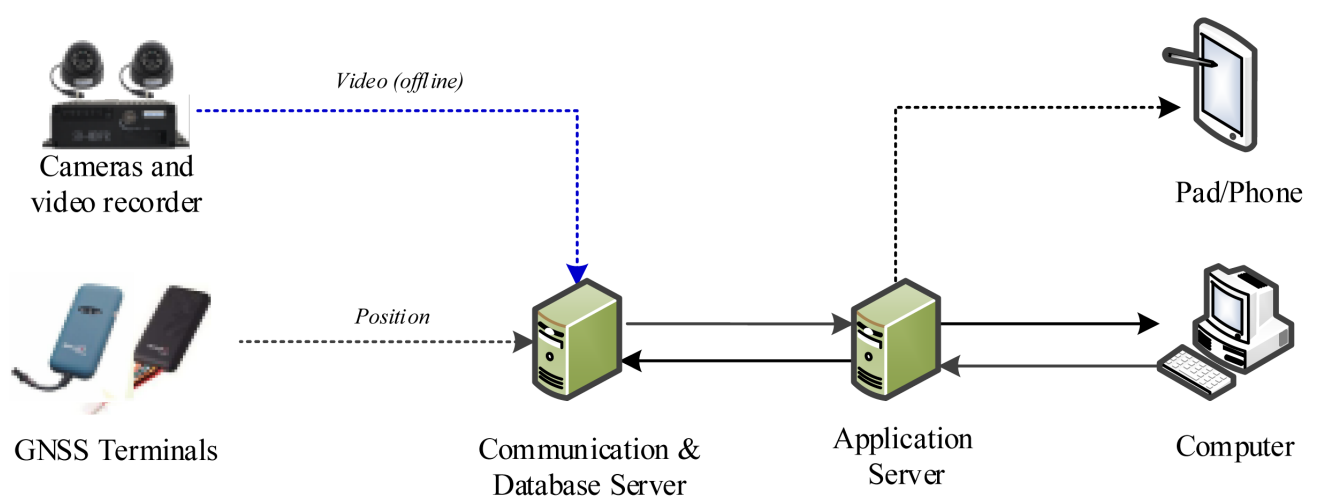

(a)

(b)

Figure 2. GNSS and camera based structureof monitoring system for forage harvesting of Huishan. Video recorder and GNSS termianl connect to ACC wire of tractor to get the battery power supply. Two cameras includes one front camera and one rear camera. GNSS terminals report position of tractor to server in $0.1 \mathrm{~Hz}$. 


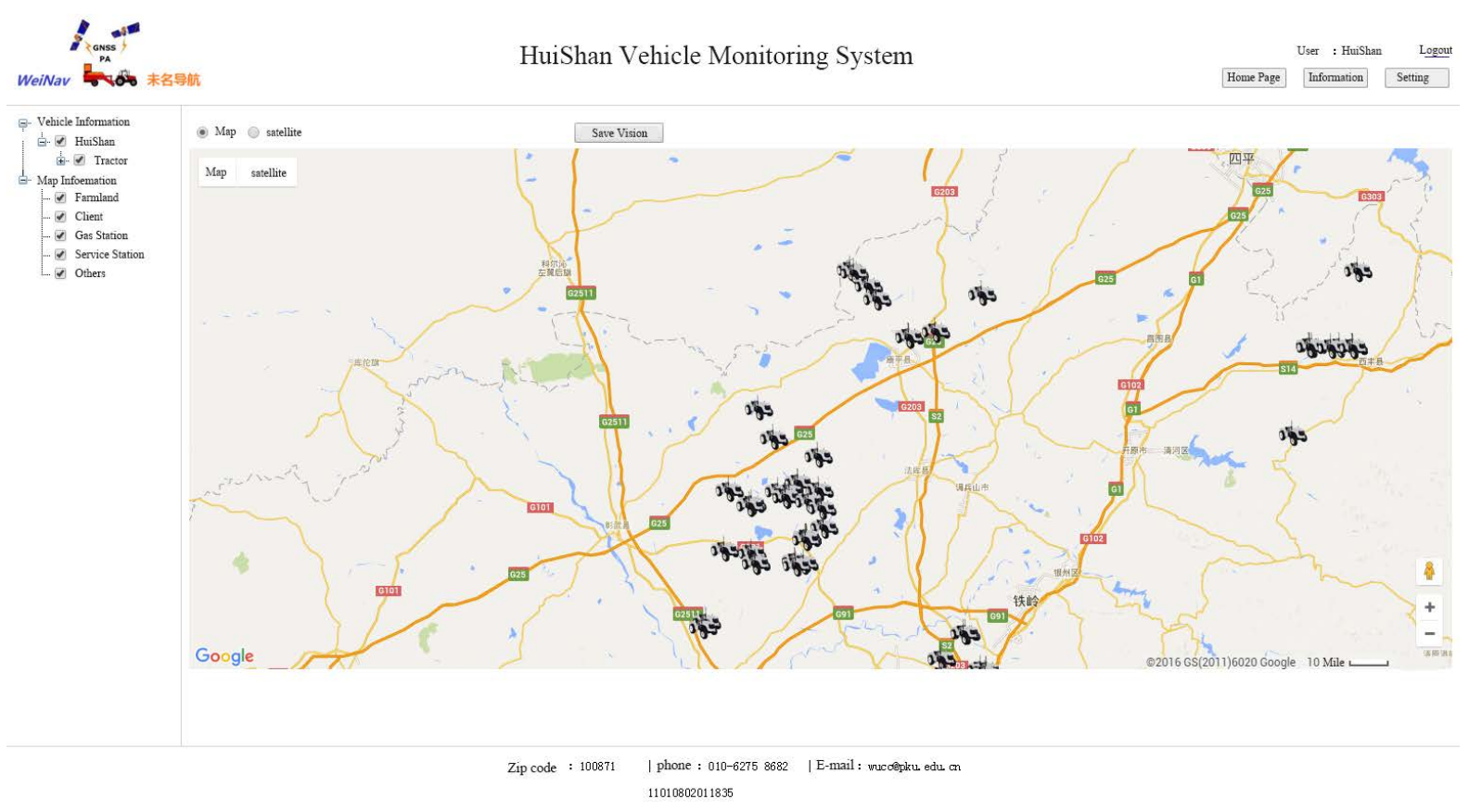

(a)

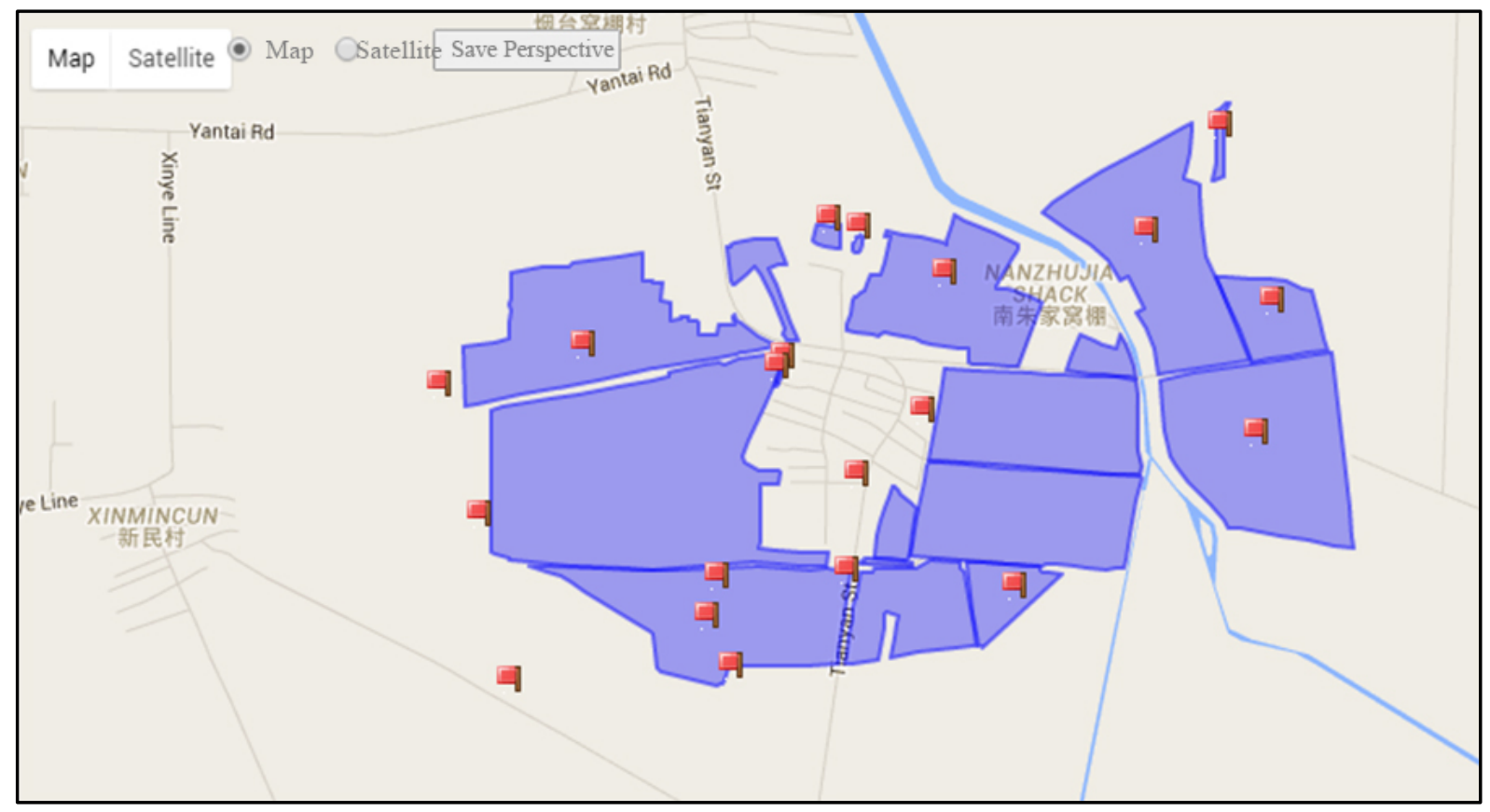

(b)

Figure 3. (a) Shows GNSS based monitoring interface of forage harvesters; (b) Shows field map of Huishan.

In further, based on method of probability and statistics, vehicle sampling module is developed for the monitoring system, to support the manager to randomly select necessary amount $(N)$ of vehicles and look through their historical tracks and videos every day. $N$ is calculated by the following formula.

$$
N=(0.95 * M) / D
$$

where $N$ is the necessary amount of vehicles should be selected each day, $M$ is the total amount of vehicles the company owns, and $D$ is the duration of farm operation (d). The model and module can release the management 
work and improve inspection efficiency.

The third influence factor, mechanical failure, causes serious problem to forage harvesting. As the above reason, drivers do not really care for the harvester. The most common accident is serious damage to header of the forage harvester. The header is an expensive part and is the most important part to the harvester. To deal with this influence factor, the company bought two or more extra headers for backup. As Figure 4 shows that new header can replace the bad one directly and quickly to save maintain time.

For the fourth influence factors, operation skill defects, the company will well train drivers to use farm machinery to deal with its influence.

For the fifth influence factors, machine aging, the company will buy well-known and high quality farm machinery to deal with this influence. And during the sparse time, device department of the company will repair and maintain farm machinery in time to keep good health. The monitoring system will provide abundant information for the maintain service.

\subsection{Case 2: Uncertainty and Counter Measure for Cotton Picking Company}

Xinjiang Xinjian Modern Agricultural Engineering Development Co., Ltd. (Xinjian Agri.) is a company which owns more than 400 cotton-pickers of CASE IH (CASE), John Deere (JD), and Guihang. Three kinds of cotton-picker has different machine quality, operation reliability, and operation efficiency. Nearly half of the cotton area of Shihezi District, Xinjiang, is harvested by the company. The company does not own any fields to plant cotton. It is a classical Business to Business (B2B) commercial mode to provide social service for some local farms (just like a county in China) with about 13,000 ha cotton field. The small farmers will be organized by the local farms and the latter would sign contract with Xinjian Agri. The top 5 uncertainties of Xinjian Agri. as following: 1) mechanical failure, 2) operation location change, 3) weather mutation, 4) parts supply delay, and 5) operation area change. Fire disaster is also an absolute uncertainty for cotton picking.

For the first influence factor, mechanical failure, according to several years' practice, the company decides to use the cotton-picker of CASE and JD. Guihang cotton-pickers are just used as backup, and may never be used in recent years. So when the company use the overall scheduling model and system (as Figure 5) to create machine fleet for the farms, Guihang cotton-picker will not be considered originally.

Since the cotton-picker is a relatively clumsy machine, it will stay and work in a farm in whole picking season. When general manager of the company dispatch cotton-pickers to create machine fleet for the farms, he should judge the completion rate of the current machine fleet, and compare the completion rate among the entire machine fleets. As Figure 5, with the histogram, his scheduling work became easier than before. For big farms, such as Farm 121, Farm 148, they will be allocated two or three machine fleets. For small farms, the completion rate is usually equal to or somewhat higher than $100 \%$, while for big farms, it might be lower than $100 \%$ but higher than $90 \%$, to ensure all farms can be finished by allocated machine fleets. The reason is that big farm has more cotton-pickers and has higher capacity to resist uncertainty. Machine fleets can extend operation time or operation duration to release potentials. And low planning completion rate will also encourage the drivers to

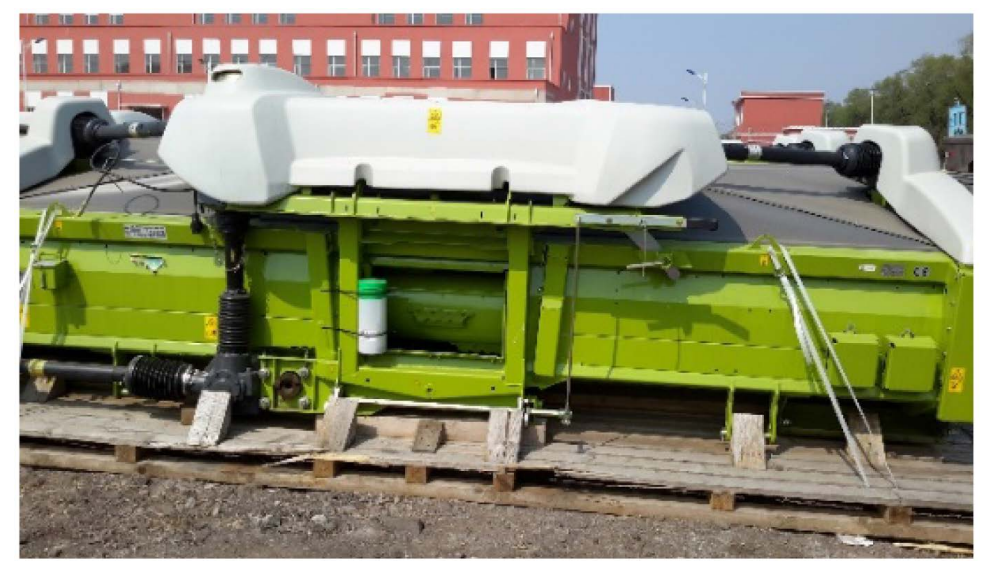

Figure 4. New header of forage harvester for backup to deal with uncertainty influence. 


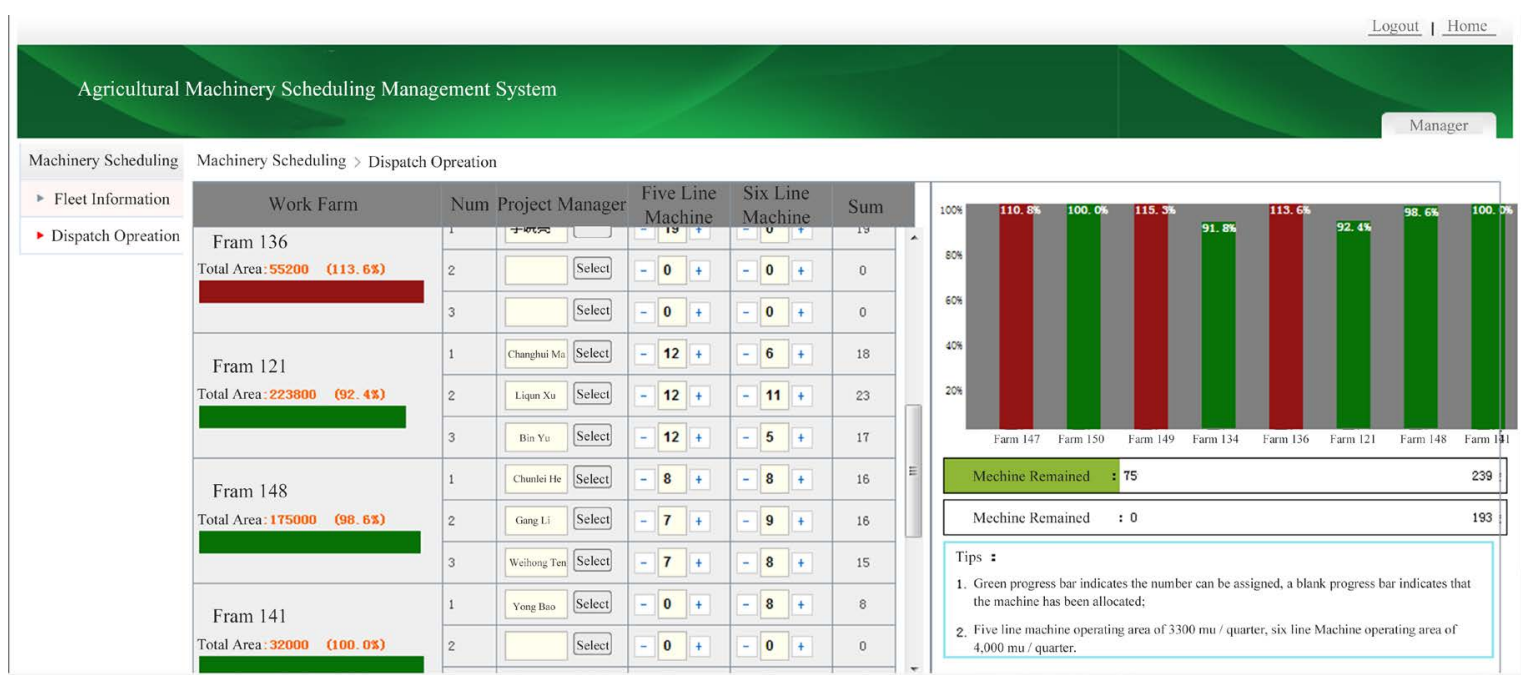

Figure 5. The interface of overall operation scheduling to allocate cotton-picker quota and to create machine fleet according to the requirements of cotton plantation farms.

work harder. If possible, the planning completion rate would be higher than $100 \%$, which would be better to deal with the fifth influence factor (operation area change). The practice showed that the operation scheduling accorded with the reality. All the machine fleets finished their task in 2015 in time.

The second influence factor, operation location change, will happen every day. To deal with this influence, the company need the monitoring and central navigating system to guide the machine unit to the destination. Smart phones are assigned to captain of machine unit. He could receive commands of dispatching and central navigating, and APP (see Figure 6) of smart phone can initiate APP of Baidu Map, then the APP will navigate the machine unit to specific field.

The third influence factor, weather mutation, is a factor that cannot be reversed. All the cotton-pickers have to stop working when the weather is bad.

The fourth influence factor, parts supply delay, has high correlation with the first influence factor (mechanical failure). If the cotton-picker does not suffer mechanical failure, it does not need any parts. But if the cottonpicker often suffers mechanical failure, it usually needs parts and repair service. To deal with this influence, the service man also need to know location of the broken-down cotton-picker. And he uses the central navigating technology and system to guide him to the broken-down cotton-picker (see Figure 6).

\subsection{Case 3: Uncertainty and Countermeasure for Social Service Cooperative}

Beijing Xingnongtianli (XNTL) Professional Service Cooperative of Farm Machinery owns about 2000 ha fields and about 60 tractors and other farm machinery. The cooperative will provide social service for other villages and farmers. From the answer sheet, we filter out influence factors including 1) mechanical failure, 2) incompatibility between agronomy and machine, 3) operation order increasing, 4) operation location change, 5) operation sequence change, and 6) field location inaccurate, which occurrence frequency not lower than "often" and influence degree not lower than "serious". Weather mutation occurs "usually", but it influence degree is also "serious". Moreover, the cooperative proposes that there are some uncertainties from internal management. It need precise method to monitor the workload of each driver.

On the basis of Case 1 and Case 2, we can deal with most of the uncertain influences by using the scheduling and monitoring model and system, GNSS terminal, and smartphone. For the uncertainties from internal management of this case, we propose a smartphone based APP to precisely monitor inputs of production factors including tractor, implement, and labors.

PMS (see Figure 7) can be used during the farm operation. When farm operation starts, the driver should scan QR codes of the tractor, driver, and implement respectively. When labor or implement changes during farm operation, the changed QR codes should be rescanned. As a result, the operation mileage and duration of each production factor can be precisely recorded and transferred to server. Then manager of the cooperative can clearly know operation area and operation duration of each driver, and give higher rewards to better drivers. 


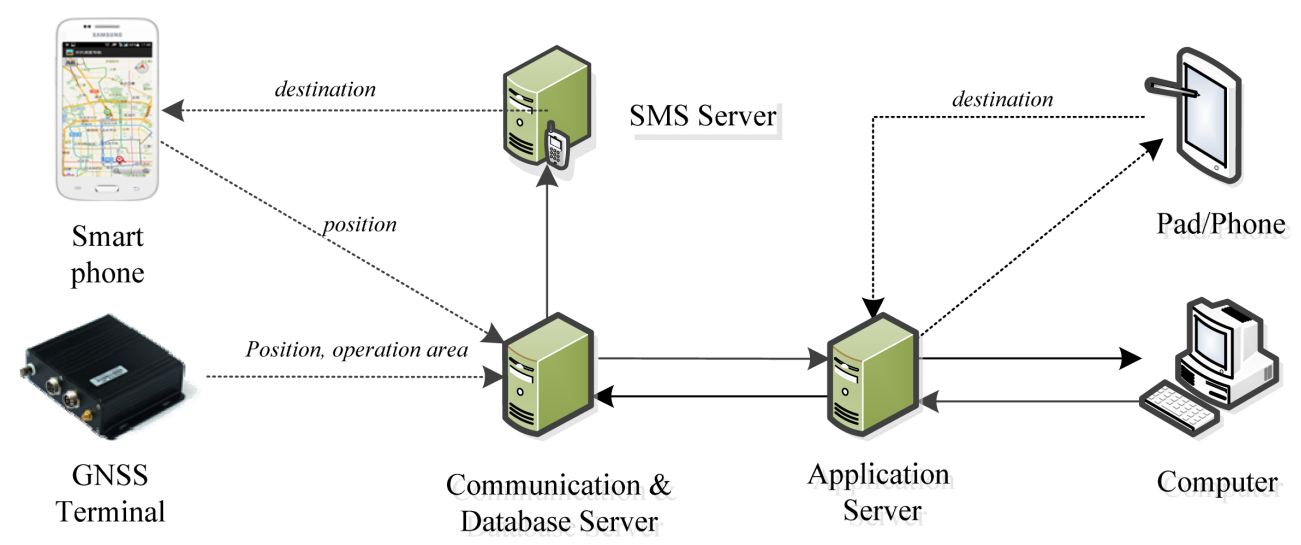

Figure 6. System structure of Cotton-picker Operation Scheduling \& Monitoring System (CPOSMS). Smartphone based APP of Baidu Map will guide the machine unit to specific field or guide service unit to the broken-down machine unit.

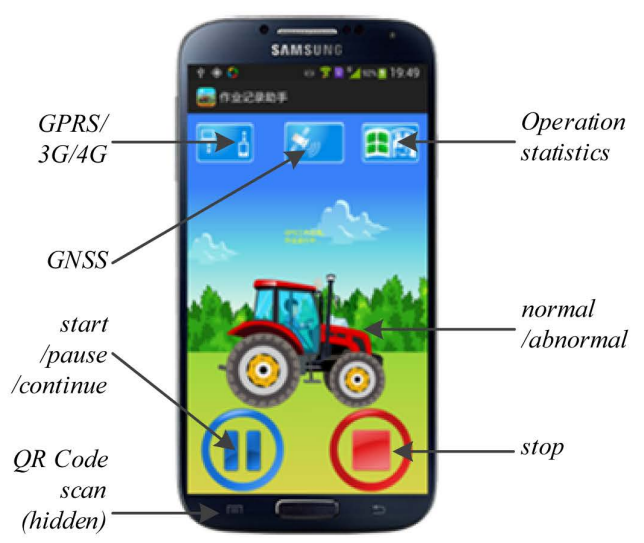

(a)

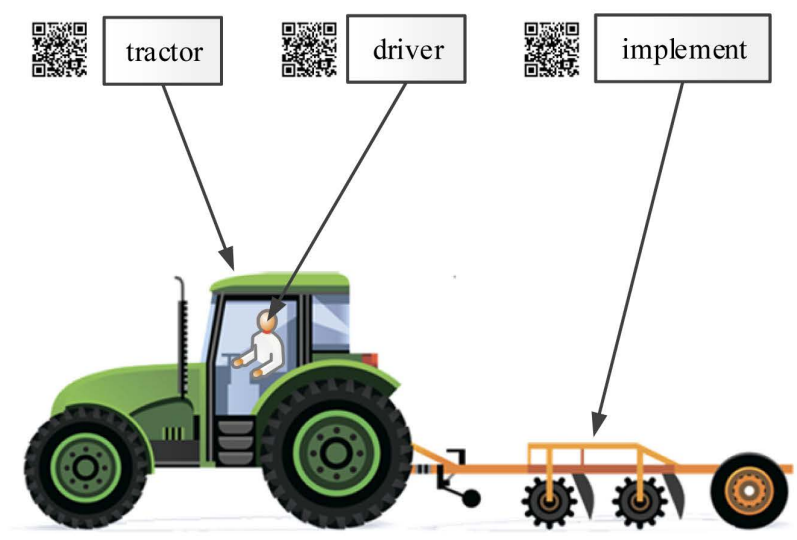

(b)

Figure 7. Smartphone based Precise Monitoring Software (PMS). (a) Shows interface of PMS; (b) Shows QR code based identification of production factors including tractor, driver, and implement.

\section{Conclusion and Discussions}

Uncertain influence factors arisen from natural environment, society and economy, market and supply, and customer and behavior, exist widely, emerge frequently, and affect farm operation deeply. Questionnaire for B2B organizations was designed and finished in 2014. Both occurrence frequency and influence degree for each influence factor were quantified. Four influence factors including operation location change, weather mutation, parts supply delay, and operation skill defects appear in both list of high occurrence and deep influence. Different organization has different influence factors.

Results of questionnaire and results of specific investigation were used to study temporal and spatial scheduling and monitoring model and system for farm machinery management. Three case studies are introduced.

1) The first case is about the uncertainty and countermeasure of forage harvesters scheduling and monitoring for China Huishan Dairy Holdings Company Ltd. (Huishan). According to assets and material losses and mechanical failure, GNSS and camera based scheduling and monitoring model systems have developed for Huishan.

2) The second case is about the uncertainty and countermeasure of cotton-picker scheduling and monitoring for Xinjiang Xinjian Modern Agricultural Engineering Development Co., Ltd. (Xinjian Agri.). According to mechanical failure and operation area increasing, an overall scheduling model system has developed to support general manager to dispatch cotton-pickers and to create machine fleet for the farms, and help him to judge the completion rate of the current machine fleet by comparing the completion rate of entire machine fleets. For operation location change, the module of central navigating is proposed to guide the machine unit to the destination. 
3) The third case is about the uncertainty and countermeasure of farm machinery social service management for Beijing Xingnongtianli (XNTL) Professional Service Cooperative of Farm Machinery. Besides the influence factors which other companies also suffer, the cooperative proposes that there are some uncertainties from internal management. According to the requirements of precise monitoring, a smartphone based Precise Monitoring Software (PMS) is developed, which can scan QR codes of production factors including tractor, driver, and implement, to record their operation area and operation duration.

The cases show that the research has strong pertinence to deal with uncertainties and can improve management efficiency of farm machinery operation.

\section{Acknowledgements}

This work is in part supported by National High Technology Research and Development Program of China (2012AA101902), Science \& Technology Pillar Program of Tianjin (14ZCZDNC00004), and part supported by Chinese Universities Scientific Fund (2014RC015).

\section{References}

[1] Guan, S., Nakamura, M., Shikanai, T. and Okazaki, T. (2009) Resource Assignment and Scheduling Based on a TwoPhase Metaheuristic for Cropping System. Computers and Electronics in Agriculture, 66, 181-190. http://dx.doi.org/10.1016/j.compag.2009.01.011

[2] Luo, M., Wu, C., Cai, Y., Su, H. and Ding, L. (2012) Mobile Monitoring and Center-Navigation Technology for Agricultural Machinery. Proceedings of American Society of Agricultural and Biological Engineers Annual International Meeting 2012, American Society of Agricultural and Biological Engineers, Dallas, 29 July-1 August 2012, 5684-5695.

[3] Bakhtiari, A., Navid, H., Mehri, J., Berruto, R. and Bochtis, D.D. (2013) Operations Planning for Agricultural Harvesters Using Ant Colony Optimization.

[4] Zhang, F., Teng, G., Ma, J. and Chang, S. (2012) Farm Machinery Scheduling and Allocating Based on Heuristic Priority Rules. Transactions of the Chinese Society of Agricultural Engineering, 28, 78-85.

[5] Senlin, G., Nakamura, M., Shikanai, T. and Okazaki, T. (2008) Hybrid Petri Nets Modeling for Farm Work Flow. Computers and Electronics in Agriculture, 62, 149-158. http://dx.doi.org/10.1016/j.compag.2007.12.006

[6] Orfanou, A., Busato, P., Bochtis, D.D., Edwards, G., Pavlou, D., Sørensen, C.G. and Berruto, R. (2013) Scheduling for Machinery Fleets in Biomass Multiple-Field Operations. Computers and Electronics in Agriculture, 94, 12-19. http://dx.doi.org/10.1016/j.compag.2013.03.002

[7] Wu, C., Cai, Y., Luo, M., Su, H. and Ding, L. (2013) Time-Windows Based Temporal and Spatial Scheduling Model for Agricultural Machinery Resources. Transactions of the Chinese Society for Agricultural Machinery, 44, $237-241$.

[8] Bochtis, D.D., Dogoulis, P., Busato, P., Sørensen, C.G., Berruto, R. and Gemtos, T. (2013) A Flow-Shop Problem Formulation of Biomass Handling Operations Scheduling. Computers and Electronics in Agriculture, 91, 49-56. http://dx.doi.org/10.1016/j.compag.2012.11.015

[9] David, A.L. (1967) Activity Network Techniques Applied to a Farm Machinery Selection Problem.

[10] Bochtis, D.D., Sørensen, C.G., Green, O., Bartzanas, T. and Fountas, S. (2010) Feasibility of a Modelling Suite for the Optimised Biomass Harvest Scheduling. Biosystems Engineering, 107, 283-293. http://dx.doi.org/10.1016/j.biosystemseng.2010.05.005

[11] Vermeulen, S.J., Challinor, A.J., Thornton, P.K., Campbell, B.M., Eriyagama, N., Vervoort, J.M., Kinyangi, J., Jarvis, A., Läderach, P., Ramirez-Villegas, J., Nicklin, K.J., Hawkins, E. and Smith, D.R. (2013) Addressing Uncertainty in Adaptation Planning for Agriculture. Proceedings of the National Academy of Sciences of the United States of America, 110, 8357-8362. http://dx.doi.org/10.1073/pnas.1219441110

[12] Gersonius, B., Gersonius, R., Ashley, A. and Pathirana, C. (2013) Climate Change Uncertainty: Building Flexibility into Water and Flood Risk Infrastructure. Climatic Change, 116, 411-423. http://dx.doi.org/10.1007/s10584-012-0494-5

[13] Dias, A.C.A.E.M., Bastian-Pinto, C.D.L., Brandão, L.E.T. and Gomes, L.L. (2011) Flexibility and Uncertainty in Agribusiness Projects: Investing in a Cogeneration Plant. RAM Revista de Administração Mackenzie, 12, 105-126. http://dx.doi.org/10.1590/S1678-69712011000400005 